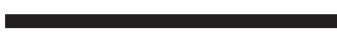

AUTORAS:

Gabriela Gurgel R. Santos Gisélia dos S. D. Picanço

Universidade do Estado do Parà

\section{A influência do treinamento resistido na vida funcional de portadores de lúpus}

\section{PALAVRAS CHAVE:}

Lúpus. Exercício físico e treinamento resistido.

\section{ABSTRACT}

The purpose of this paper was to identify the influence of resistance training on functional life of people with Lupus and whether it improves or worsens the case of these patients. It was carried out a literature search through a literary and analytical selection of articles which were used some references of authors like Borba et al (1), Póvoa (6), among others. It were analyzed seven articles where most of the authors says that strength training is suitable for people with lupus to generate numerous health benefits thereof. Thus it was concluded that resistance training provides better performance in functional activities of life by reducing the frequency of pains and stiffness in the joints, then showing that hardly will be responsible for a worsening or complication of the disease provided it is guided by a professional able to engage in this activity.

KEY WORDS:

Lupus. Exercise. Resistance training. 


\section{INTRODUÇÃo}

O número de estudos relacionados aos efeitos do treinamento resistido sobre os aspectos fisiológicos para pacientes com Lúpus ainda é limitada. Por esse motivo este artigo tem como tema a Influência do Treinamento Resistido na Vida Funcional de Portadores de Lúpus. Segundo Lindsey e Criswell (apud 6) o lúpus é uma doença autoimune, multissistêmica, caracterizada pela hiperatividade do sistema imunológico e pela produção de autoanticorpos.

Muitas pessoas portadoras dessa doença se privam de praticar tal modalidade pelo fato de alguns autores afirmarem que pessoas com lúpus devem evitar o treinamento resistido, com isso levam os leigos a se restringirem mais ainda a pratica da modalidade. Identificado isso esse estudo tem influência direta na sociedade e é de grande relevância por proporcionar a mesma o conhecimento, a segurança e uma visão mais ampla sobre a relação entre o Lúpus e o treinamento resistido, quebrando assim muitos paradigmas que restringem e em alguns casos chegam a gerar o medo e aversão a prática dessa atividade. Dessa forma o objetivo desse trabalho é realizar um estudo bibliográfico e através deste identificar as influências do treinamento resistido na vida funcional das pessoas portadoras de lúpus e se o mesmo melhora ou agrava o caso dos pacientes. Para desenvolver o estudo foi realizada uma pesquisa através de uma seleção literária e analítica de títulos, resumos e artigos.

\section{LÚPUS}

O Lúpus é uma patologia autoimune e crônica, na qual o sistema imunológico do corpo humano agride seus próprios tecidos e órgãos fazendo com que haja inflamações e lesões que comprometem a funcionalidade dos mesmos. Para Martinez et al. (s/n) o lúpus é definido como uma doença inflamatória crônica, de causa multifatorial, de natureza caracterizada por presença de autoanticorpos em essencial contra antígenos nucleares, alguns dos quais se associam a lesão em vários órgãos alvos.

Essa doença causa alterações no funcionamento dos linfócitos B e linfócitos T. Esta disfunção imunológica pode ser devido a uma ativação de células B policlonais que induz a produção em grande número de autoanticorpos. Segundo Mattije e Turato ${ }^{(\mathrm{s} / \mathrm{n})}$ o caráter do Lúpus é autoimune, isto é, o próprio sistema imunológico ataca os próprios tecidos do indivíduo, representando um fenômeno da natureza: uma produção de autoanticorpos ocorre e outras células do sistema imune juntam-se a luta provocando inflamações e depósitos que conduzem ao dano do tecido. Os autoanticorpos e o complexo imune agridem geralmente as articulações, músculos, pele, rins, coração, sangue, vasos sanguíneos, pulmões, fígado, pâncreas, sistema nervoso central e sistema cardiovascular. Com isso as funções e o condicionamento desses órgãos ficam debilitados.
As manifestações mais comuns em relação aos sintomas são as dores de cabeça, febre, fadiga, e a perca de peso, que ocorrem de forma intervalada na doença, podendo ser ativos ou não. As complicações mais graves da doença são as musculoesqueléticas, uma das mais comuns é a poliartrite crônica que segundo o Dicionário de Termos Médicos são inflamações simultâneas de várias articulações, dependendo da fase ela pode vir acompanhada de várias outras manifestações. Outra complicação comum é a osteoporose, quase sempre desenvolvida pela falta de vitamina $D$, pelo uso exacerbado de medicamentos, inatividade física, entre outros.

Baseado no estudo de Castro (7) o lúpus é uma patologia incomum que acomete com mais frequência as mulheres jovens. No Brasil a incidência é em média de 8,7 casos por 100 mil habitantes em cada ano. Pressupõem-se que o surgimento da patologia está relacionada a predisposição genética e fatores ambientais, na verdade, sua etiologia ainda é desconhecida, não há predominância em raça, cor da pele e etnia.

Por muito tempo, houve um aumento considerável na mortalidade devido a essa patologia, mas esse quadro vem diminuindo cada vez mais, graças aos avanços nos estudos científicos, nas técnicas terapêuticas e em medicamentos que interferem na proliferação da doença.

\section{TRATAMENTO DO LÚPUS}

\section{RELACIONADO Á ATIVIDADE FíSICA}

É comprovado cientificamente que o Lúpus não tem cura, é um caso irreversível, porém, há formas de tratamento que amenizam os sintomas provocados pela doença e que melhoram a vida funcional do portador. Esses tratamentos podem ser medicamentosos ou terapêuticos; o tratamento mais utilizado é o medicamentoso, que sua vez não é suficiente para que esses indivíduos tenham uma vida funcional de qualidade. Segundo Borba et al. (1) existem algumas medidas gerais que fazem parte das medidas terapêuticas no tratamento do Lúpus e dentre as modalidades citadas pelo autor está a atividade física.

A vida funcional dos portadores de Lúpus se torna muito limitada pelas diversas complicações adquiridas em consequência dessa patologia, 90\% das pessoas com esse diagnóstico têm um comprometimento nas articulações onde estão localizadas as dores e isso acaba privando-as de alguns movimentos, pois, são as articulações que auxiliam e permitem ao ser humano ter mobilidade para subir uma escada, correr, pular, agachar, carregar uma sacola de compras, enfim, estas pessoas são restringidas das atividades mais simples do dia-a-dia de uma pessoa dita "normal". Outra questão que contribui para essa limitação é a fadiga muscular que ocorre de forma mais antecipada com estas pessoas sem que façam muito esforço físico. 
Ultimamente o exercício físico junto com os benefícios que traz para a vida de seus praticantes tem ganhado espaço na área cientifica onde muitos estudiosos têm mostrado sua importância e comprovado que ele previne e até mesmo reverte quadros que por uma visão leiga não seria reversível. No entanto, com toda essa gama de conhecimento a respeito do exercício físico, algumas pessoas ainda recomendam o repouso para os pacientes com Lúpus restringindo-os da atividade física. 0 grande problema é que estes não levam em consideração que o sedentarismo, ou a falta de movimento muitas vezes só agrava a situ ação pelo fato de deixar o corpo destas pessoas cada vez mais debilitado devido a grande fraqueza muscular já existente.

Segundo Póvoa ${ }^{\left({ }^{6}\right)}$, há pouca evidência científica sobre qual o melhor tipo de exercício físico para os pacientes com Lúpus, mas sua importância é reconhecida. Vale ressaltar que a atividade física a partir de seus excelentes resultados mostra que é segura e confiável desde que seja bem orientada por um profissional da área capacitado para exercer atividades seguras não só para o Lúpus, mas também para qualquer outra patologia.

\section{TREINAMENTO RESISTIDO E LÚPUS}

0 treinamento resistido ou treinamento de força, é definido por Forjaz et al. ${ }^{(s / n)}$ como exercícios nos quais ocorrem contrações voluntárias da musculatura esquelética de um determinado segmento corporal contra alguma resistência externa, ou seja, contra uma força que se opõe ao movimento, sendo que essa oposição pode ser oferecida pela própria massa corporal, por pesos livres ou por outros equipamentos, como aparelhos de musculação, elásticos ou resistência manual. Esse tipo de treinamento tem sido nos últimos tempos uma das modalidades de atividade física mais praticada na sociedade e também tem sido indicado para pacientes com Lúpus como procedimento não medicamentoso, porém alguns autores defendem a tese de que esta prática é muito ariscada e que deveria ser evitada no meio destes pacientes.

A eficácia do treinamento de força para este público tem sido muito questionada, este assunto é de extrema importância e requer uma ampla discussão. Há estudos de pacientes com Lúpus engajados em programas de treinamento resistido regulares que apresentaram melhor desempenho em atividades da vida diária por diminuir a frequência de dores e a rigidez nas articulações, ou seja, adquiriram uma melhora significativa na vida funcional.

Em relação aos benefícios para as complicações musculoesqueléticas, o treinamento resistido pode diminuir as dores e rigidez das articulações, podendo aumentar a força e diminuir a fadiga muscular causada pela doença por atacar o sistema imunológico, assim melhorando a vida diária do paciente, pois age diretamente na musculatura esquelética que ajuda nas movimentações funcionais.
0 treinamento resistido é subdivido em duas modalidades que facilitam mais ainda a realização do mesmo com os pacientes de lúpus: o treinamento estático e o dinâmico, no qual o estático faz um trabalho isométrico que não há movimentação articular, é indicado a realização nos estágios em que há mais inflamação nas articulações. Ricks ${ }^{(\mathrm{s} / \mathrm{n})}$ afirma que esta modalidade gera menos inflamação e menos pressão infra-articular, podendo ser eficaz na prevenção de atrofia muscular. No entanto, se for realizado de maneira sustentada por muito tempo pode desencadear problemas cardíacos, especialmente em pacientes com lúpus e com acometimentos cardíacos. Já o treinamento dinâmico exige mais o trabalho articular age em alongamentos e encurtamentos da fibra muscular, o que acarreta a geração maior de força ${ }^{(6)}$.

Esses exercícios podem ser trabalhados de formas adaptadas relacionadas ao limite da dor, amplitude de movimento e de cansaço respeitando a individualidade e restrições de cada pessoa. Isso acaba com o tabu de que o treinamento de força prejudica ou agrava mais ainda os processos inflamatórios das articulações dos pacientes. Pois há um processo de avaliação do exercício em relação à afetividade e a segurança da realização dos mesmos.

0 fato de essa modalidade ser indicada para esse público não quer dizer que o mesmo pode ser praticado de qualquer forma ou sem precauções, existe assim como em outras modalidades a necessidade do entendimento dessa metodologia e de capacitação para que se possa prescrever o mesmo.

\section{RESULTADOS}

Na pesquisa de dados foram encontrados diversos artigos relacionados ao Lúpus e a Atividade Física, porém depois da seleção literária e analítica de títulos, resumos e artigos apenas sete artigos foram utilizados dentre os quais apenas quatro tratam do Treinamento Resistido e sua influência na vida funcional de portadores de lúpus.

Dentre estes artigos, dois tratam da importância da atividade física para a qualidade de vida de pessoas com Lúpus. Apenas um dos artigos defende a tese de que pessoas com lúpus deveriam evitar o treinamento resistido pelo fato do mesmo ser considerado uma modalidade muito intensa para estas pessoas que tem uma vida funcional muito limitada devido às diversas complicações adquiridas. Segundo esse artigo as pessoas com esse diagnóstico têm um comprometimento nas articulações e uma fadiga muscular exagerada que ocorre mais rapidamente, dessa forma são pessoas debilitadas que deveriam ser restringidas de muitos esforços físicos. Os últimos quatro artigos relatam que o treinamento de força é indicado para este público. Estes autores apresentaram em seus artigos que o treinamento resistido proporciona melhor desempenho em atividades da vida funcional por diminuir a frequência de dores e a rigidez nas articulações. 
A partir dessa revisão bibliográfica de fontes seguras entre os contras e os prós é comprovado que a prática do exercício resistido dentro dos seus limites para portadores de lúpus é benéfica e apresenta resultados positivos para estes. Este treino proporciona melhoria nas capacidades físicas, funcionais e funções imunológicas do organismo dos portadores da doença, ou seja, ele é indicado por proporcionar a melhora nas atividades diárias dessas pessoas desde que seja exercida de acordo com as individualidades de cada um.

De acordo com as pesquisas muitas pessoas que são portadoras de Lúpus não praticam treinamento de força por não conhecerem os benefícios que este pode trazer para sua saúde, a falta desse conhecimento gera em muitos o medo de agravar seu estado com a prática dessa atividade.

Diante disso nota-se a importância de um trabalho multidisciplinar entre o profissional que descobre o diagnóstico do Lúpus e o profissional que intervém no tratamento deste através do treinamento resistido. A partir do momento em que o médico informa ao seu paciente que o mesmo é portador da doença ele também está apto a indica-lo a um profissional da área de Educação Física que possa conduzir este paciente a prática de uma atividade física que o ajude na otimização de suas tarefas diárias e o treinamento resistido é uma modalidade que pode de fato ser indicada pelos estudos que tem comprovado sua eficácia para estes pacientes.

Muitos pacientes de Lúpus não se submetem a este tipo de treinamento por falta de confiança ou insegurança profissional, dessa forma seria muito válido que houvesse locais de atendimento especializados para este público, ou seja, que houvessem academias com profissionais especializados em atendimento para pessoas com Lúpus. Dessa forma levarem a estes pacientes mais segurança em saber que o profissional que estará the atendendo estará apto para isso e saber quais os procedimentos a serem tomados para que se obtenham os resultados que almejam.

É necessário que haja mais profissionais, educadores físicos que desenvolvam trabalhos com esse público para cada vez mais levar conhecimento e segurança principalmente para os portadores da patologia que as vezes se restringem a essa pratica por falta de informação de fontes seguras.
1. BORBA, C.J, Carvalho MC, Silva NS, Bezerra JC, Drigo AJ, Dantas EH. A Força Muscular, Densidade Óssea e Composição Corporal de uma Mulher com Lúpus Eritematoso Sistêmico Submetida a um programa de Trenamento de Resistência. Rev. Bras Med Esporte. 2010. 2. SATO. et al. Lúpus eritematoso sistêmico: acometimento cutâneo/articular. Rev Assoc Med Bras. 2006. 3. JESUZ A. K, CAMARGO R. S, Modalidades De Tratamento No Lúpus Eritematoso Sistêmico: Revisão de Literatura, 2000 A 2010. Cadernos da Escola de Saúde. Curitiba, vol.2. 2010

4. OLIVEIRA, M.N, Lúpus Eritematoso Sistêmico, uma Revisão de Literatura das Características, Diagnósticos e Tratamentos. Brasília. DF, 2011.

5. LEITE, Cátia Fernande, et. al. Efeitos aa Prátic Regular de Exercícios Físicos por Portadores de Lúpus Eritematoso Sistêmico: Estudo de Revisão. UNICAMP, Campinas, v. 11, n. 3, jul./set. 2013

6. POVOA, T.I.R. Lúpus Eritematoso Sistêmico Exercício Físico e Qualidade de Vida. Artigo de Revisão. Revista Digital, Buenos Aires. Maio, 2010

7. CASTRO, Paulo. Estudo comprova que treino muscular alivia sintomas do lúpus Campus Universitário Darcy Ribeiro, Brasília - DF, Copyright 2008 Universidade de Brasília. 